\title{
(3) Liver Diseases
}

\author{
Hideo Nagashima
}

First Department of Internal Medicine, Okayama University Medical School

This report is concerned with an autoimmune mechanism in chronic liver diseases, especially with an analysis of patients with active chronic hepatitis and cirrhosis of the liver observed in our clinic.

The results were as follows:

1) Six cases with chronic liver diseases showed clinically the characteristics of autoimmune phenomena described by Mackay et al. These cases associated with a positive L. E. cell test included 2 with lupoid hepatitis, which showed subacute yellow liver atrophy and postnecrotic cirrhosis, respectively, and 1 with active chronic hepatitis progressing to precirrhosis after recurrent jaundice, 1 with cirrhosis of the liver (postnecrotic cirrhosis) and 2 with SLE associated with viral hepatitis and serum hepatitis.

2) Of 104 cases with chronic liver diseases, the percentage incidence of positive L. E. like cell reaction was 22.5 per cent in active chronic hepatitis, 57.1 per cent in precirrhosis and 40.8 per cent in cirrhosis of the liver, and also in 663 cases with hepatitis and cirrhosis of the liver the percentage of positive antiliver antibody was $36.2-45.5$ per cent.

The percentage incidence of simultaneous positive serological reactions of both antiliver antibody and L. E. like cell phenomenon was in the range of $60-70$ per cent or more in chronic liver diseases.

3) In the ANF test, the method of Lachmann, P. J. et al. was followed in all but minor respect. Bright homogeneous rat liver and human lymphocyte nuclear phenomena were observed in cases with active chronic hepatitis and cirrhosis of the liver. These cases never showed SLE symptoms during the course of the diseases. This result suggests that the positive ANF described above may result from liver cell damage.

4) There was no correlation between the intrahepatic lymphoid focus formation (or piecemeal necrosis) and the positive serological reactions (antiliver antibody and $\mathrm{ANF}$ ) in chronic liver diseases.

5) The characteristics of antiliver antibody were analyzed in liver diseases and the following results were obtained.

a) The percentage of positive antiliver antibody was higher in chronic stage of viral hepatitis $(36.7-45.5 \%)$ than in acute stage of the diseases (16.7-31.8\%).

b) The antiliver antibody formation could not always be suppressed by the 
treatment with corticosteroids.

c) Antiliver antibodies were dominant in $7 \mathrm{~S}$ fraction by means of DEAE column chromatography and saline or succurose density gradient cenrifugation.

d) Cross-reactions for other organ antigens from the kidney, spleen and lung etc. as well as liver antigen were observed, but sera with chronic liver diseases showed higher specificity against the liver than against other organ antigens.

e) Anticomplementary effect showed in some sera from chronic liver diseases, moreover the determination of the antiliver antibody was possible according to the 3 stage complement fixation reaction by Rapp, H. J. et al.

f) Secondary responses were observed by injections of interenin, $\mathrm{ACTH}$ and cortisone, when antiliver antibodies disappeared from circulating blood in cases with liver disease and in the course of viral hepatitis, and also significantly increased titers of circulating antiliver antibodies occurred immediately after relapsing or at the 3rd to 5th day after deterioration of clinical symptoms.

6) Immune clearances of ${ }^{51} \mathrm{Cr}$ labelled tanned rat erythrocytes (TRE), TRE coated with rat liver antigen and anti-rat liver rabbit serum in normal mice were examined. (A suspension of $2.5 \times 10^{8} \mathrm{TRE} / \mathrm{ml}$. was labelled with $50 \mu \mathrm{c}$. of ${ }^{51} \mathrm{Cr} / \mathrm{ml}$.). Blood clearance was performed as described by Benacerraf, B. et al. $\mathrm{Cr}^{51}$ TRE with rat liver antigen and anti-rat liver antibody were eliminated faster $\left(\mathrm{K}_{4}=0.022\right)$ than ${ }^{51} \mathrm{Cr}$ labelled with only rat liver antigen $\left(\mathrm{K}_{3}=0.013\right)$ or ${ }^{51} \mathrm{Cr}$ labelled TRE alone $\left(\mathrm{K}_{2}=0.01\right)$.

7) Isolated rat liver cells were cultured at 24 hours in culture media (TC-199 or Hanks' solution), and were sensitized with anti-rat liver rabbit sera at $37^{\circ} \mathrm{C}$ for 3 hours, then these rat liver cells were incubated with rat liver antigens coated with latex particles (Difco Bacto latex 0.81 ) at $37^{\circ} \mathrm{C}$ for 30 minutes or tanned rat erythrocytes sensitized with rat liver antigens at room temperature for 2 hours in culture media.

Micrograph of rat liver cells showed very large number of latex particles or rat erythrocytes attached to outer liver cell membranes in the absence of complement.

Rat liver cells $(500,000 / \mathrm{ml}$.) were sensitized with anti-rat liver antibodies with or without complement from rat or guinea pig in culture media such as TC-199 or Hanks' solution, and then the liberation of enzymes [glutamic dehydrogenase, isocitric dehydrogenase, transaminases (GOT, GPT)] from these liver cells were examined.

More enzymes were released in the presence of antisera and/or complement than in the presence of normal rabbit sera or liver cells in culture media alone. From these results antiliver antibodies may have possible pathogenetic roles to injure liver cells in vitro experiments. However, the possibility of the pathogenetic roles of antiliver antibodies in vitro must be more exactly examined.

8) Lymphocytes were isolated from popliteal lymphnodes of the rabbits sensitized with rat liver antigens or from peripheral blood of cases with active chronic hepatitis or cirrhosis of the liver by the method of Coulson, A.S. et al. These lymphocytes in Hanks' solution were incubated with rat or human liver antigens coated with latex particles at $37^{\circ} \mathrm{C}$ for 30 minutes. The lymphocytes in reaction mixture were washed by a large amount of Hanks' solution, and smears were then made and stained by 
May-Grünwald-Giemsa. Very large number of latex particles attached to outer lymphocyte membranes.

This experiment suggests the possibility that these lymphocytes coated with latex particles may contain cytophilic antibodies against liver antigens. 